\title{
Laboratory simulation of blast loading on building and bridge structures
}

\author{
M. M. Gram ${ }^{1}$, A. J. Clark ${ }^{1}$, G. A. Hegemier ${ }^{2} \&$ F. Seible ${ }^{2}$ \\ ${ }^{1}$ MTS Systems Corporation, Eden Prairie MN, USA \\ ${ }^{2}$ Department of Structural Engineering, Jacobs School of Engineering, \\ University of California, San Diego, La Jolla, California, USA
}

\begin{abstract}
There is a need to modify structural elements of buildings and bridges in order to improve the response to blast loads. Testing the modifications has been a major stumbling block to advances. Failure modes resulting from a 1 to $10 \mathrm{~ms}$ blast impulse are substantially different from the failure modes obtained with conventional laboratory structural tests. Field tests using actual explosions are expensive, are not repeatable, and the fireball makes visual and video viewing impossible and reliable real-time data very difficult to obtain.

The University of California, San Diego and MTS Systems Corporation were funded to design and build a system able to perform laboratory blast simulations. The system, which was completed in 2005 at UCSD, has been used to test modified and unmodified reinforced structures including: concrete columns $355 \mathrm{~mm}$ square by $3 \mathrm{~m}$ high; and concrete block walls $200 \mathrm{~mm}$ thick by $3 \mathrm{~m}$ high. By January 2006, over 20 specimens were tested, with specimen failure modes matching the failure modes from field tests. The system uses impact loading to produce a $2 \mathrm{~ms}$ pulse with a typical peak pressure loading of $35 \mathrm{MPa}$ and an impulse of $14 \mathrm{kPa}$-s over the surface of the column. The system allows observation of the test in person and by high-speed video, as well as successful instrumentation of the specimen.

This paper describes the blast simulation system and its capabilities. Keywords: blast simulator, blast hardening, blast mitigation, infrastructure protection.
\end{abstract}




\section{Background}

Terrorist attacks world-wide have demonstrated our vulnerability to threats in the form of conventional and improvised explosives. Such threats have mandated the development, validation and deployment of blast resistant new construction, and hardening retrofit techniques for existing structures. Efforts to accomplish objectives in this area are underway at the Powell Structural Research Laboratories at the University of California, San Diego (UCSD) as part of the international TSWG (Technical Support Working Group) blast mitigation program.

The development and validation of blast resistant design methodologies for new and existing structures requires high fidelity data that is repeatable and available in sufficient quantities. A similar statement applies to the problem of validating and/or improving design or blast physics computational tools.

It is evident that field testing of structural components and assemblages are necessary to complete this process. As a result, UCSD has been performing a range of field tests at sites such as the Energetic Materials Research and Testing Center (EMRTC) of New Mexico Tech (our partner in the TSWG blast mitigation program) and the Naval Air Warfare Center Weapons Division at China Lake, California.

It is also evident, however, that field experiments are limited by constraints on costs and time. In addition and perhaps more important, reliable real-time field data are very difficult to obtain and the fireball renders visual and high speed video viewing of failure processes virtually impossible.

In an effort to expand the quality and quantity of blast experiments in an affordable and timely manner, UCSD and MTS were tasked and funded by the TSWG to design and build a system able to perform blast load simulations on typical structural components in a laboratory environment. The result is the UCSD Blast Simulator, the world's first hydraulically driven device that simulates explosive loads without the use of explosive materials, and without a fireball. In what follows, the design and performance of the Blast Simulator are described.

\section{Concept}

In field-testing, an explosion produces a pressure pulse that can be measured using pressure transducers distributed on the test specimen. The impulse (momentum) is calculated from the pressure data. The challenge was to develop a test system to reproduce that impulse by a method that was suitable for a laboratory. In response to that challenge, UCSD and MTS, worked together, to develop the Blast Simulator. The technology used in the Blast Simulator was developed by MTS Systems for production of test equipment requiring high energy impacts: artillery firing simulators, automotive crash simulators, shock testing equipment, and high rate material test systems.

The concept of the Blast Simulator is to produce an impulse by impacting the specimen with a mass. An elastomeric spring between the impacting mass and 
the specimen distributes the force over the uneven surface of the specimen. The impacting mass is brought up to velocity. The impact transfers the energy and momentum from the impacting mass to the specimen. The spring rate of the elastomer determines the duration and the peak force of the impact pulse.

There is a need to study and test many types of structures, so the Blast Simulator must be adaptable. By using multiple actuators with an impacting masses attached to each, the system can be configured to test a wide variety of structures. The requirement for controlling the momentum delivery system then, must include precise impact timing, as well as, precise impact velocity, in order to simulate an actual blast.

\section{The Blast Impulse}

A standard technique for analyzing structures subject to a blast is to use the impulse (time integral of force); this technique is considered accurate for structures having a response time greater than 3 times the length of the impulse (response time is defined as the time to peak displacement) [1]. Therefore, the Blast Simulator elastomeric springs must provide a short pulse similar in length to those measured in field tests.

Table 1: Technical specifications for the Blast Generator.

\begin{tabular}{|c|c|}
\hline Blast Generator & \\
\hline Quantity & 4 \\
\hline Maximum energy (each) & \\
\hline With mass: $50 \mathrm{~kg}(110 \mathrm{lb})$ & $30 \mathrm{~kJ}$ \\
\hline $100 \mathrm{~kg}(220 \mathrm{lb})$ & $51 \mathrm{~kJ}$ \\
\hline $200 \mathrm{~kg}(441 \mathrm{lb})$ & $76 \mathrm{~kJ}$ \\
\hline $400 \mathrm{~kg}(882 \mathrm{lb})$ & $101 \mathrm{~kJ}$ \\
\hline Maximum velocity & \\
\hline With mass: $50 \mathrm{~kg}(110 \mathrm{lb})$ & $34 \mathrm{~m} / \mathrm{s}(1300 \mathrm{in} / \mathrm{s})$ \\
\hline Repeatability of velocity & $4 \%$ or $0.1 \mathrm{~m} / \mathrm{s}$ whichever is greater \\
\hline Simultaneous impact & Within $0.002 \mathrm{~s}$ \\
\hline Impacting Mass & \\
\hline Mass range (bolted to BG rod) & $\begin{array}{l}50 \text { to } 400 \mathrm{~kg}(110 \text { to } 882 \mathrm{lb}) \text { (includes mass } \\
\text { of piston) }\end{array}$ \\
\hline Mass range (free mass) & 10 to $50 \mathrm{~kg}(22$ to $110 \mathrm{lb})$ \\
\hline Impact Spring & \\
\hline Impulse time & 0.5 to $5 \mathrm{~ms}$ \\
\hline Linearity (non-linearity) & $\begin{array}{l}\text { Spring rate to increase with increasing } \\
\text { deflection to prevent an overly abrupt } \\
\text { impulse initiation. }\end{array}$ \\
\hline Mounting of impact spring & Bolts to face of impacting mass \\
\hline
\end{tabular}


A strategy for creating a simulation equivalent to an actual blast when either pulse is too long is to use finite element analysis to calculate a correction factor. A finite element analysis of the blast pulse on the structure determines the work put into the structure by the blast, then an impact velocity can be determined (using finite element) that subjects the structure to the same work.

In the simulation, the mass attached to the Blast Generator is accelerated to a velocity. The resulting momentum $=$ mass $\mathrm{x}$ velocity. Momentum from the impactor is transferred to the specimen during the impact. The momentum transferred is a function of the mass of the impactor, the mass of the specimen, and the damping of the elastomeric spring. The actual momentum or impulse delivered to the specimen during a test is calculated from accelerometer data and Blast Generator pressure transducer data. The specifications for the Blast Generator are listed in Table 1.

\section{$4 \quad$ Blast Generator}

In order to develop the energy or momentum to test the specimen, the Blast Generator actuator must accelerate the impacting mass to a velocity up to $30 \mathrm{~m} / \mathrm{s}$ (1200 in/s) within a stroke of about $1 \mathrm{~m}$ (40 in). This hydraulic actuator, together with the control valves, accumulators and transducers, is referred to as a Blast Generator (BG). A schematic diagram of the BG is shown in Figure 1.

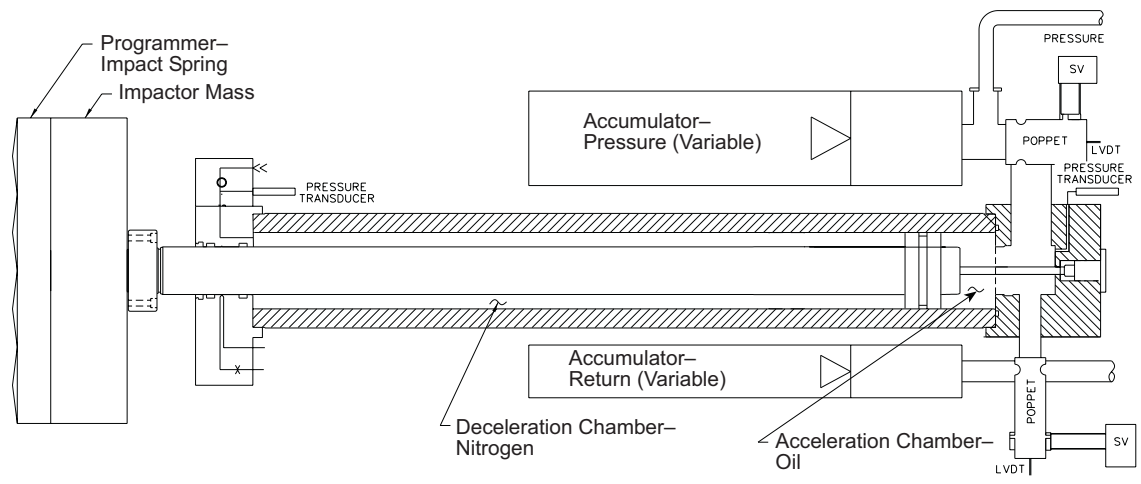

Figure 1: $\quad$ Blast Generator schematic.

The actuator can produce a maximum force of about $250 \mathrm{kN}(56000 \mathrm{lbf})$ to accelerate the impacting mass. To provide the peak flow for the test, nitrogen is compressed in the pressure accumulator to store a volume of high-pressure oil. The servo-controlled high-flow valve controls the oil flow into the acceleration port of the actuator. Potential energy in the accumulator is converted, in the actuator, to kinetic energy in the impacting mass. A smaller servo-controlled valve controls flow out of the acceleration port to retract the actuator after the impact. The force to retract the actuator is supplied by pressurized nitrogen gas that fills the retract, or deceleration, chamber of the actuator. In a conventional actuator, oil is used in the retract chamber; in the BG, nitrogen gas is used to minimize energy loss. 
The time to accelerate the mass to a stable impact velocity is typically $40 \mathrm{~ms}$. A close-coupled, pressure-line accumulator incorporated into the BG assembly provides the fast flow response required to supply the needed energy. A close-coupled, return-line accumulator accommodates the flow from the retract valve.

The two high-flow valves are servo controlled, using the LVDT feedback on valve position. During the test, the pressure valve opening is controlled precisely to form the control orifice needed to achieve the desired impact velocity and impact timing. During setup the two valves are operated together providing position control for the actuator.

Pressure transducers provide readings of all the actuator pressures to allow precise setup and to measure actuator forces during impact. Each actuator position is measured and controlled using externally mounted Temposonic ${ }^{\circledR}$ magnetostrictive position transducers. The differentiated stroke transducer output provides an accurate measure of impact velocity.

A steel plate, bolted to the end of the piston rod provides the impacting mass. An elastomer spring is mounted to the mass. The impacting face of the elastomer spring is contoured to provide an initially low contact spring rate that progressively increases-this contouring reduces excitation of high frequency vibrations in the impacting mass and the specimen. The elastomer spring is shown in Figure 2.

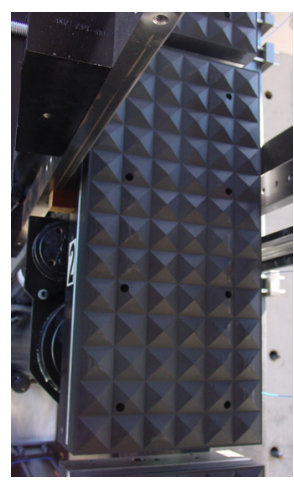

Figure 2: $\quad$ Elastomer spring.

\section{Control system}

The computer based control system controls BG positions during test setup. During the test, it provides the valve commands to generate the desired impact velocity and timing on the four BGs. After the test, it retracts the BGs and returns them to a safe state. A computer model of the BG is used, for each test, to determine the setup values for oil and nitrogen pressures, initial position, and valve command profile to achieve the desired impact velocity.

The control system was initially designed to run tests with all actuators impacting at the same velocity. After conducting tests for several months, the 
UCSD researchers saw a need for tests simulating a bomb close to the column specimen with higher impulse (velocity) at the lower end of the specimen and reduced impulse on the higher BGs. MTS was able to accommodate this need with a minor change to the software. The system is able to run tests with impact velocities varying over a 3:1 range, still maintaining simultaneous impact.

\section{Instrumentation and data acquisition}

Control and setup transducers include three pressure transducers on each Blast Generator, LVDT stroke transducers on the control valves, and a Temposonic stroke transducer used to control actuator position and measure velocity at impact. Accelerometer(s), mounted on the impacting mass, record impact data for calculating force and impulse. Output of all the BG control system transducers is digitally recorded at $4 \mathrm{kHz}$ for each test. The accelerometer output is recorded at $800 \mathrm{kHz}$.

The specimen instrumentation system was configured by UCSD. Transducer selection varies to suit the test requirements and includes accelerometers, stroke transducers, and strain gages. Data acquisition, triggered by the control system, can record 52 channels of 14-bit data at $1 \mathrm{MHz}$. The high-speed data acquisition can also record data from any of the control transducers, when desired.

Two Phantom version 7.1 high-speed video cameras, capturing 5000 frames per second, provide a graphical capture of specimen failure, and can also provide velocity and deflection measurements of the specimen.

\section{$7 \quad$ Measuring the impulse}

The force on the elastomeric spring acts equally on the specimen and the impacting mass. Forces acting on the impacting mass are: specimen force on the elastomer pad, friction on the bearings, and BG internal forces. Thus the specimen force is the inertial force (acceleration times impacting mass), minus friction, plus BG force. The impulse measurement is as follows:

- Accelerometers mounted on the impacting mass measure the acceleration during the impact

- $\quad$ Friction force can be calculated or measured (approximately) and subtracted. It is very small and is usually ignored.

- The BG is controlled to provide low acceleration at the point of impact. This holds the BG forces relatively low during impact-generally $<5 \%$ of inertial force.

- The pressure transducers measure the internal pressures in the BG actuator, and the force is calculated. The speed of sound in steel and oil causes a delay of about $1 \mathrm{~ms}$ between the transducer and accelerometer data. This delay is calculated (based on actuator position at impact) and the force during impact is recorded and added as a correction to the inertial force.

- The resulting force, on each impactor, is integrated over the time of the pulse to find the impulse delivered to the specimen. 
Accelerometers mounted at various locations on the specimen can be used to calculate specimen velocity and displacement during the test.

\section{Foundation}

The isolated foundation has a reinforced concrete reaction wall at each end, as shown in Figure 3. The fixed reaction wall has a steel mounting plate for mounting the BGs. For tests to date, the BGs have been mounted in a vertical column utilizing t-slots in the wall to provide adjustment. The mounting plate allows other BG mounting locations as required.

The moveable reaction wall provides a moveable link system for the upper end of the specimen. The moveable reaction wall is re-configurable. It is constructed from large reinforced concrete blocks that are stacked and posttensioned to the foundation. Fixtures have been built to allow simulations of end conditions on the specimen matching those in actual structures.

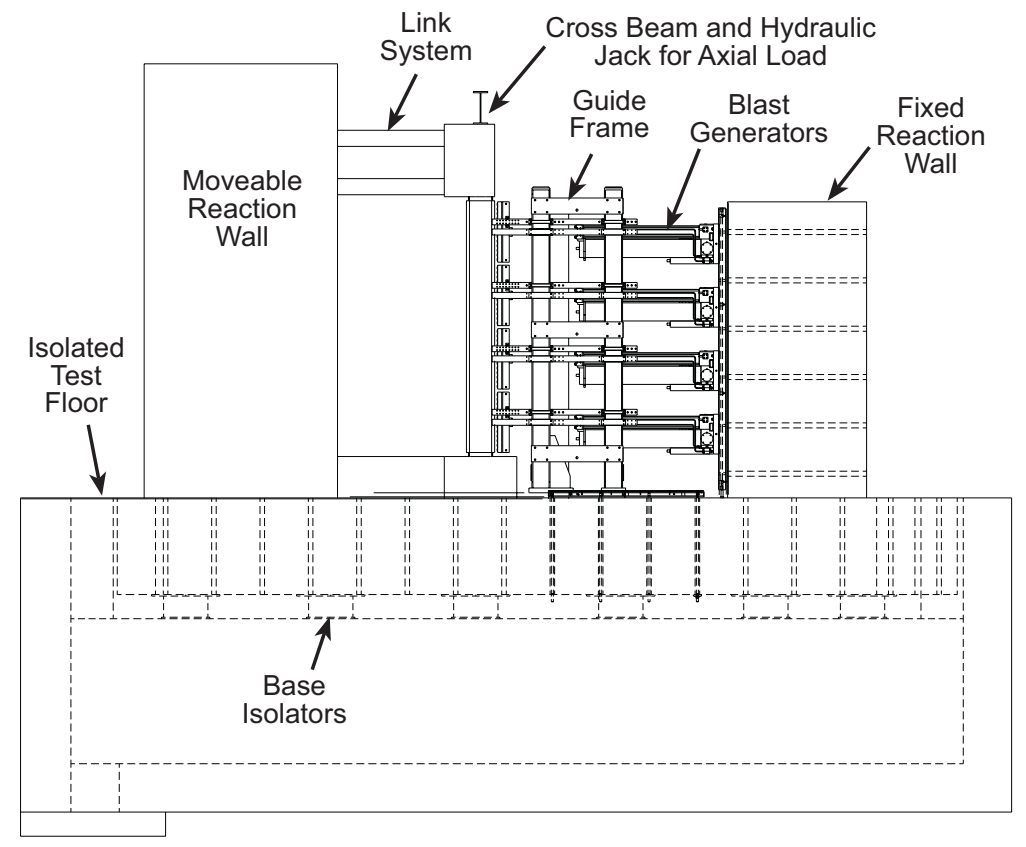

Figure 3: Foundation.

Guide rails are used to support the weight of the impacting masses and keep them aligned with the specimen. The guide rails are attached to an adjustable frame that allows spacing between BGs to be adjusted. It also adjusts to accommodate several sizes of impacting masses. The stroke transducers are mounted to the guide frame, and provide a direct reading of the position of the impacting mass. A photo of the guide frame can be seen in Figure 4. 


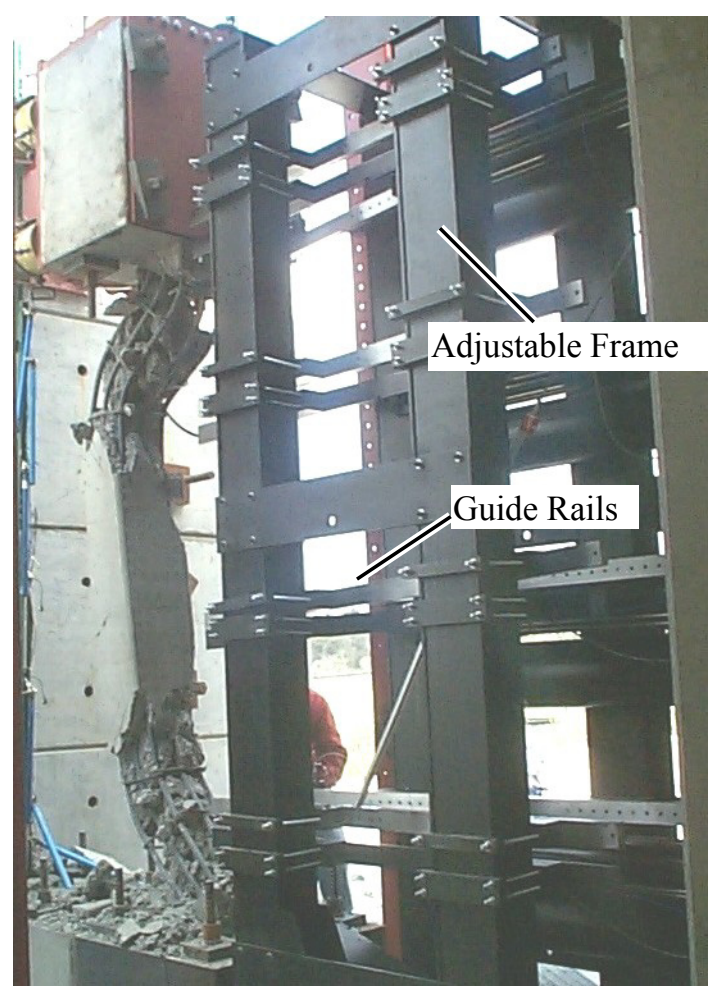

Figure 4: Guide frame (shown with broken specimen).

\section{Infrastructure}

The blast simulator is part of the Englekirk Center, a multi-hazard research facility of the University of California, San Diego about eight miles east of the main UCSD campus. In addition to the Blast Simulator, the center includes two other major research projects: The world's largest outdoor earthquake simulation table-the LHP Outdoor Shake Table; and the Soil Foundation Structure Interaction (SFSI) program, which includes a large laminar soil shear box and two refillable soil pits.

The three facilities share a hydraulic power supply that includes an accumulator bank for providing peak hydraulic flow of 40,000 1/m (10,000 gpm).

The very temperate San Diego climate allows test equipment to be operated outside throughout the year. By locating the equipment outside, full scale specimens can be built and installed using conventional construction techniques. The site has a 55-ton truck-crane available for all the test rigs.

The Blast Simulator is connected to the hydraulic power supply and uses $34 \mathrm{MPa}$ (5000 psi) pressure for primary flow, as well as $21 \mathrm{MPa}$ (3000 psi) for pilot pressure. The accumulator bank flow is also available to simulate after-theblast loading on the specimen. 
The Blast Simulator foundation is sited so that the BGs are located inside the building, and the specimen is outside the building. An outdoor preparation area adjacent to the system is used for building and curing specimens. As one test is completed, the truck crane can quickly move a new specimen into position for mounting, post tensioning, instrumenting, and testing.

\section{Blast Simulator performance}

Performance of the Blast Simulator has been evaluated to-date using BG-on-BG impacts, and column and wall test specimens loaded with groups of three or four BGs at impact velocities from $1.5 \mathrm{~m} / \mathrm{s}(4.9 \mathrm{ft} / \mathrm{s})$ to $30 \mathrm{~m} / \mathrm{s}(98 \mathrm{ft} / \mathrm{s})$. Below, we present a subset of the column test data as an indicator of performance.

\subsection{Description of test specimen and test setup}

The columns to be discussed are reinforced concrete (RC) with full-scale dimensions of $3.28 \mathrm{~m}$ (129 in) in length and $355.6 \mathrm{~mm}$ (14 in) square. These are loaded with four BGs distributed over the column length as depicted in Figure 2. The impact mass plates measure $355.6 \mathrm{~mm}$ (14 in) wide by $762 \mathrm{~mm}$ (30 in) tall and have a mass of $243 \mathrm{~kg}(535.7 \mathrm{lbs})$. The reaction fixtures are similar to those used in previous quasi-static tests of blast resistant column designs conducted by $\operatorname{UCSD}[2,3]$. At the column base, the footing is post-tensioned to the test floor in an effort to restrain all degrees of freedom. At the top of the column, a link system allows the column to move vertically while providing lateral and rotational fixity. Vertical axial load is applied at the top of the load stub by three hydraulic jacks with a mechanical lock-off. The jacks react against a steel frame. This test setup is intended to simulate the boundary and loading conditions associated with an actual building configuration. (Details of the test setup can be found in Seible and Hegemier [4] and Hegemier et al. [5]).

\subsection{Energy deposition signature}

The force-time histories associated with the mass plates plus programmer-specimen impacts, as determined by acceleration-time histories, reflect a pulse width of 2 to $4 \mathrm{~ms}(0.002$ to $0.004 \mathrm{~s})$ depending on the programmer type and the impact velocity. In addition, simultaneity of impacts (see Figure 5) can be achieved in a range of $0.3 \mathrm{~ms}$ to $2 \mathrm{~ms}$ depending on the test settings and conditions.

\subsection{Impulse histories}

Typical impulse histories are shown in Figure 6 along with the overall (averaged) impulse. In general, the overall impulse can be delivered in 3 to $5 \mathrm{~ms}$ with amplitudes up to $20.7 \mathrm{kPa}$-s (3 psi-s). An impulse of $14 \mathrm{kPa}-\mathrm{s}$ (2 psi-s) is representative of a "car bomb at curb side". 
42 Structures Under Shock and Impact IX

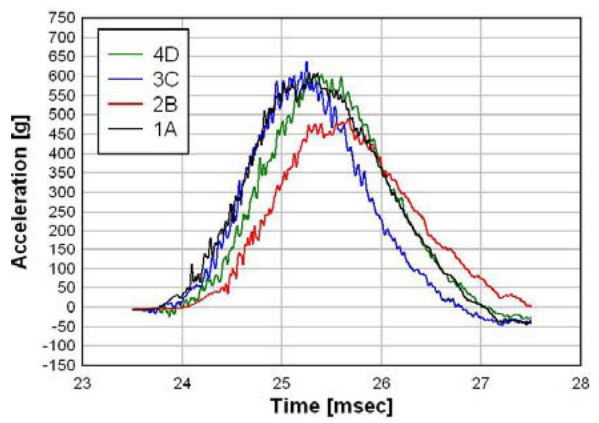

Figure 5: $\quad$ Typical simultaneity of BG hits ( $0.3 \mathrm{~ms}$ spread).

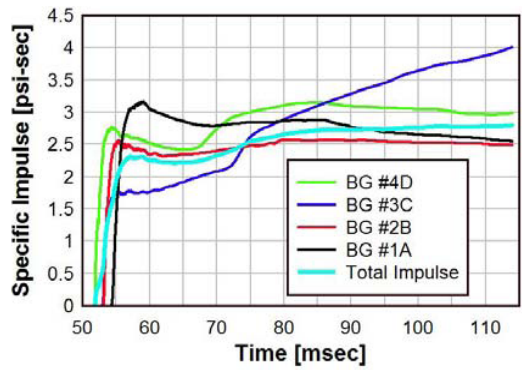

Figure 6: Impulse histories.
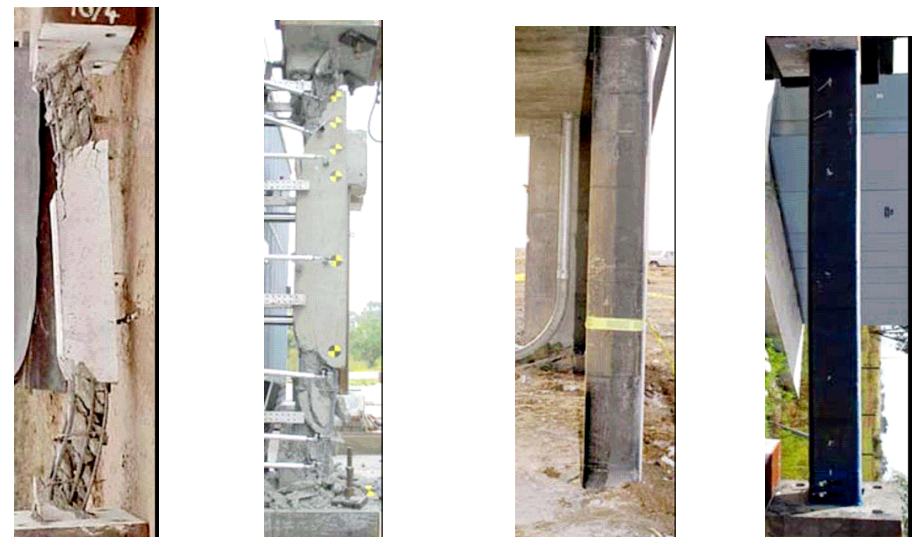

Figure 7: From left to right: RC column (field test), RC column (blast simulator test), CFRP wrapped column (field test), CFRP wrapped $\mathrm{RC}$ column (blast simulator test). 


\subsection{Comparison of laboratory and field tests}

Comparison of post-test laboratory and field data from similar tests conducted on similar test specimens have revealed excellent correlation of impulse, deformation, and failure mode, thus showing the blast simulator accurately simulates live explosive loads. Example comparisons of laboratory and field impulse and failure modes are shown in Figures 7 and 8, respectively, for a "car bomb at the curb" scenario. Finally, it is emphasized that the absence of the fireball associated with the field event allows one to follow the specimen failure-time history. This is dramatically illustrated in Figure 9 which is a frame sequence from high speed video record of a RC column subjected to a $15.8 \mathrm{kPa}-\mathrm{s}$ (2.3 psi-s) event. In the field, such information is typically obscured by the fireball and the debris field.

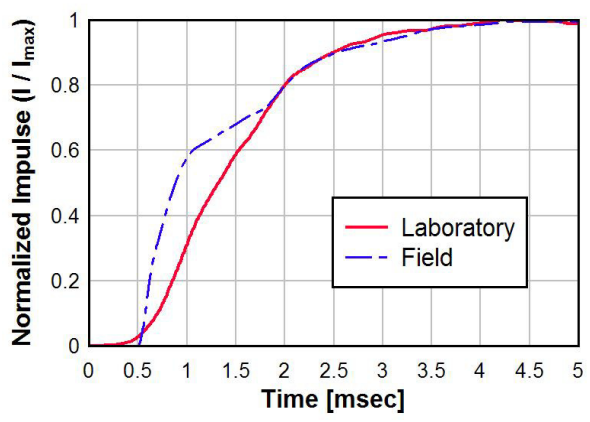

Figure 8: $\quad$ Impulse comparison.
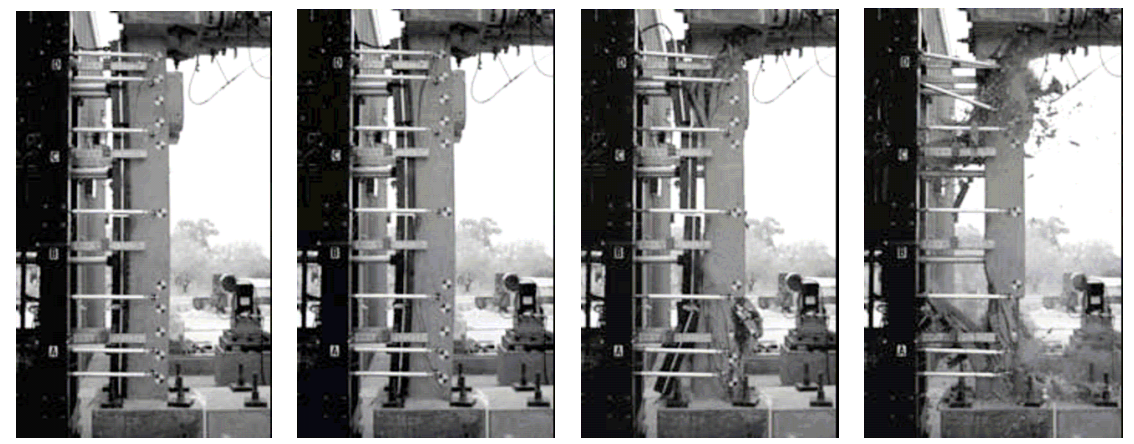

Figure 9: Damage evolution of an as-built column under blast simulator impact.

\section{References}

[1] Joint Departments of the Army, the Navy, and the Air Force, "Structures to Resist the Effects of Accidental Explosions", TM 5-1300/NAVFAC P397/AFR 88-22 
[2] Hegemier, G., Seible, F., Rodriguez-Nikl, T., Lee, C., Budek, A.M., \& Dieckmann, L. 2002. FRP-Based Retrofit Strategies - Laboratory Tests on Rectangular RC Columns, Report No. SSRP-2002/04, UCSD, Department of Structural Engineering.

[3] Hegemier, G., Seible, F., Lee, C., \& Rodriguez-Nikl, T. 2003. FRP-Based Retrofit Strategies - Laboratory Tests on Rectangular RC Columns - Part II, Report No. SSRP-2002/17, UCSD, Department of Structural Engineering.

[4] Seible, F. \& Hegemier, G. 2005. Shakedown and Commissioning Final Test Report. TSWG Contract Deliverable.

[5] Hegemier, G., Seible, F., Rodriguez-Nikl, T. \& Arnett, K. 2006, in press. Blast Mitigation of Critical Infrastructure Components and Systems. Proceedings of the Second fib Conference, Naples, Italy, June 2006. 